\title{
Laryngeal Adenosquamous Carcinoma
}

National Cancer Institute

\section{Source}

National Cancer Institute. Laryngeal Adenosquamous Carcinoma. NCI Thesaurus. Code C54338.

A rare, aggressive carcinoma that arises from the larynx. It is characterized by the presence of squamous cell carcinoma and adenocarcinoma components. Hoarseness, sore throat, and dysphagia are the presenting symptoms. 